\title{
Costs and efficacy of management measures to improve udder health on Dutch dairy farms
}

\author{
K. Huijps,${ }^{* 1}$ H. Hogeveen, ${ }^{*} \dagger$ T. J. G. M. Lam, $\ddagger$ and A. G. J. M. Oude Lansink† \\ *Department of Farm Animal Health, Faculty of Veterinary Medicine, Utrecht University, Utrecht, the Netherlands \\ †Chair Group Business Economics, Wageningen University and Research Center, Wageningen, the Netherlands \\ fDutch Udder Health Center at GD Animal Health Service, Postbus 2030, 7420 AA, Deventer, the Netherlands
}

\section{ABSTRACT}

Many different management measures are available to control mastitis, a very costly disease in the dairy sector. The objective of this paper was to evaluate the costs and efficacies of 18 of these management measures, for contagious and environmental pathogens, and their effect on bulk tank somatic cell count (BTSCC) and incidence of clinical mastitis (CM). To determine the efficacies for these management measures, literature data and expertise were combined using Monte Carlo expert evaluation analysis. The effect of management measures varied with the incidence of CM and BTSCC, as well as for environmental and contagious problems. On average, postmilking teat disinfection was found to be the most effective measure in all situations. All management measures had large uncertainty around the most likely value. Results of a data envelopment analysis showed that 4 of the management measures included formed the best-practice frontier (the most cost-efficient measures): keeping cows standing after milking, rinsing clusters after milking a clinical case, using a separate cloth for all cows, and wearing milkers' gloves. Of the top 25 management measures (the 18 base management measures including levels of compliance), 8 were measures with $100 \%$ compliance; the others were sublevels of these measures with compliance varying between 25 and $100 \%$. A lower hourly rate of the farmer did not influence management measures from the best-practice frontier, but had some effect on the efficiency scores of the other management measures.

Key words: mastitis, decision support, management efficacy, data envelopment analysis

\section{INTRODUCTION}

Mastitis is an endemic disease in the dairy sector worldwide and causes, among others, serious economic consequences (Halasa et al., 2007). Mastitis expresses

Received May 22, 2009.

Accepted September 24, 2009.

${ }^{1}$ Corresponding author: k.huijps@uu.nl itself in 2 ways: subclinical mastitis with bulk tank somatic cell count (BTSCC) as an often-used parameter and clinical mastitis (CM) expressed as the incidence rate of CM (Barnouin et al., 2005). It is difficult to control mastitis because it is a multifactorial disease, has numerous causative bacteria, and can be transmitted from cow to cow (contagious mastitis) and from environment to cow (environmental mastitis). The primary source of contagious pathogens is infected mammary glands. Spread of these pathogens within a herd occurs mainly during milking. Environmental mastitis pathogens reside in the environment where cows live. Control of environmental mastitis pathogens is best achieved by maintaining a clean, dry environment for lactating and nonlactating cows and by optimizing host resistance. The multifactorial nature of mastitis means that there are many risk factors for mastitis, requiring several different management measures to control.

In daily practice, advice given on management measures is often based on intuition. Consequently, farmers sometimes receive contradictory advice from different sources, leading to a low adoption rate of any measures. Literature on the efficacy of management measures mostly gives general values that are not applicable in a farm-specific situation. Additionally, for most farmers and advisors it is not feasible to summarize all studies and effects found to obtain an overview of the efficacy of the management measures in relation to the accompanying costs. Economic consequences of management measures are often omitted in advice and decision support, despite being a very important consideration for farmers. Quantitative data on continuous variables are usually a prerequisite for sound decision-making. Preferably, such data are derived from field studies and experiments. However, these data are often not (yet) available or, if available, incomprehensive, unreliable, or only indirectly applicable. This results in decisions being made without correct and complete information. In such situations, expert judgment is the only way to gain the required knowledge (Seabrook, 1984).

It is known that factors other than technical factors play a role in differences between farmers (Seabrook, 
1984; Barkema et al., 1999). It is, for example, only by consistent application of control practices that the maximum effect will be achieved. Although in decision support it is assumed that management measures are implemented completely and correctly, management attitude and the application quality of management practices are not always easy to determine. To account for this phenomenon, compliance levels and their effects were included in this study.

The objective of this paper was to analyze the efficacies of management measures regarding mastitis and their accompanying costs, specified for contagious and environmental pathogens, and their effect on BTSCC and CM. Furthermore, data envelopment analysis was used to express the joint effect of the management measures in relation to their costs in a technical efficiency index.

\section{MATERIALS AND METHODS}

\section{Management Measures}

As a first step, we selected the management measures for which we needed information about efficacies for a mastitis problem, varying from $100 \%$ environmental to $100 \%$ contagious. Efficacies specified on BTSCC and on the incidence of CM were needed. These management measures came from the 10-point plan of the National Mastitis Council (www.nmconline.org) that was the base of the more specific management measures as advised by the Dutch Udder Health Center (Table 1).

\section{Efficacy of Management Measures}

Two kinds of inputs were used to determine the efficacy of different management measures. First, an extensive literature search was carried out. All peer-reviewed papers in scientific journals from 1996 to 2006, and papers describing field experiments from 1986 to 2006, were searched. A structured search was conducted on the ISI Web of Science (apps.isiknowledge.com), based on a combination of terms. First, papers about mastitis, somatic cell count, or bulk milk were selected. These papers were then searched for one or more of the terms dairy, bovine, cattle, heifer, and cow. Finally, papers were selected from the above set if they contained the management measures included in this study (Table 1). Results as described in these papers had to be quantified as a percentage decrease in BTSCC or in incidence of $\mathrm{CM}$ related to one of the management measures. Selected papers were scored from 0 (not relevant) to 3 (very relevant), based on availability of data, country, materials and methods, and the potential to recalculate the data from the paper to a percentage decrease in

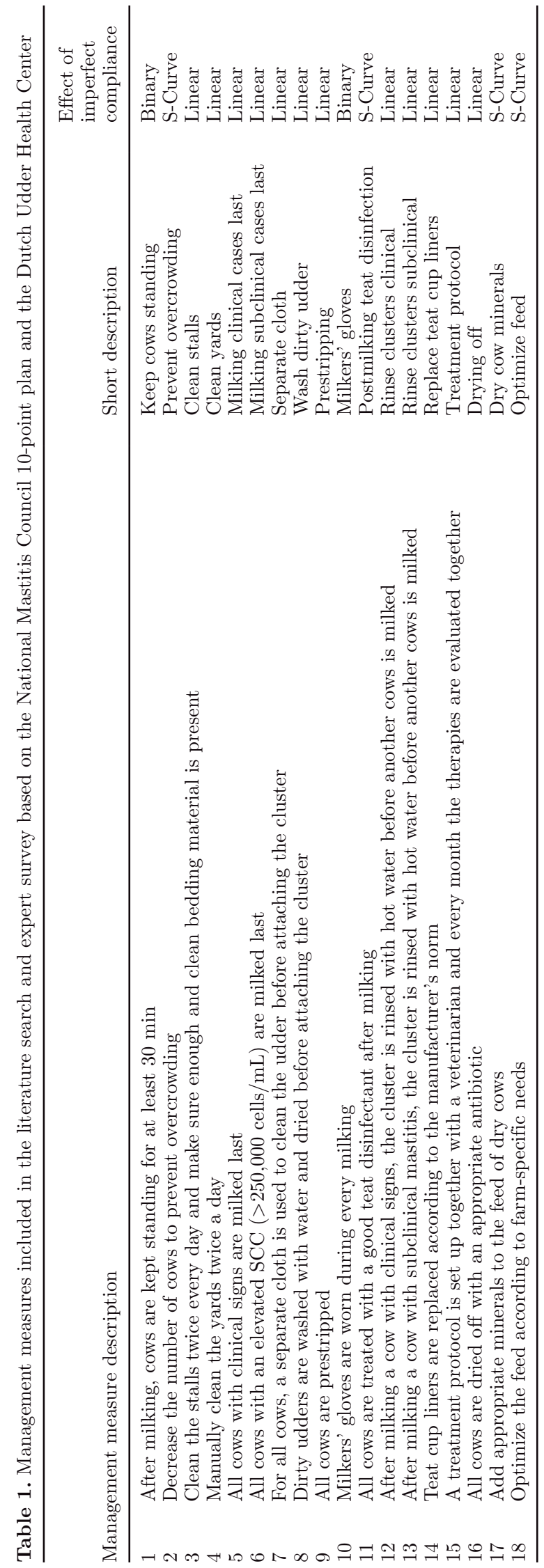


BTSCC or incidence of CM. Because the literature was incomplete, expert opinions were additionally included based on a questionnaire. To reach experts from different fields, 3 expert sessions were organized: one for dairy farmers, one for veterinarians, and one for experts from different milk and feed industries. Experts from the dairy industry were the dairy farm and mastitis experts in their company and are well-known persons in the field of mastitis. The expert veterinarians were experienced practitioners in the veterinary expert panel of the Dutch Udder Health Center. The farmers in our study were those involved in the farmers' advisory group of the Dutch Udder Health Center. These 2 panels of the Dutch Udder Health Center (one for veterinarians and one for farmers) have to advise the center in research as well as knowledge-transfer issues related to activities to improve udder health. The experts were asked to indicate minimum, most likely, and maximum effects for every management measure, specified for a $100 \%$ environmental mastitis problem and a 100\% contagious mastitis problem. They were asked to indicate these effects for a default farm, defined as a farm under Dutch circumstances, with 65 milking cows, a milking parlor with 12 places, a BTSCC of 200,000 cells $/ \mathrm{mL}$, and a clinical mastitis incidence of 30 cases per 100 cows per year (thus, 20 cases for the default herd). In the default situation, $65 \%$ of the mastitis problems were caused by environmental mastitis pathogens and $35 \%$ by contagious mastitis pathogens.

The results of the expert sessions and the literature search were combined to determine the efficacy of the management measures using Monte Carlo expert evaluation analysis. Analysis was carried out using @Risk (Palisade Corporation, Ithaca, NY). To represent the uncertainty in the values given by the experts (minimum, most likely, and maximum values), a distribution was assigned for every expert answer. This distribution was a constant value when only the most likely value was given, a uniform distribution when the minimum and maximum were given, and a triangular distribution when the minimum, most likely, and maximum were given.

After reaching convergence, defined as no more than a 1\% change of the standard deviation of the outcome, values of all individual experts were combined in one overall pert distribution representing the final expert minimum, mean, and maximum value. As a last step, expert-based values were combined with literature findings, where the combined value of the experts was assigned to the weighing factor 1 , and literature was assigned weighing factors of $2,1,0.5$, and 0 , respectively, for relevancy scores $3,2,1$, and 0 . This resulted in a minimum, most likely, and maximum value of efficacy for all management measures (Figure 1).

\section{Compliance}

Because many management measures can be implemented using variable levels of precision and completeness, 3 sublevels of compliance were included: 1) $75 \%$ compliance, 2) 50\% compliance, and 3) $25 \%$ compliance. The values derived from literature and experts were assumed to represent $100 \%$ compliance $\left(\boldsymbol{C}_{\max }\right)$. Three different types of effects of imperfect compliance were defined. The first type included management measures that had a binary effect and were assumed to be either implemented or not implemented, without the possibility of partial compliance. The second type was a linear effect type, which meant that the effect on a decrease in incidence of CM and BTSCC decreased linearly with a decreasing compliance. The third type was an S-curve effect type for management measures, which had a changeover point (formula [1]):

$$
\begin{aligned}
& \text { Effect }= \\
& C_{\text {max }} / 1+\text { shape }^{\left[\left(\text {effect }_{\text {start }}+\left(\text { effect }_{\text {end }}-\text { effect }_{\text {start }}\right) / 2-C\right)-\left(\text { effect }_{\text {end }} \text { effect }_{\text {start }}\right)\right]}
\end{aligned}
$$

where $C_{\max }$ is the maximum compliance derived from literature and experts, effect $t_{\text {start }}$ is the minimum compliance level needed to start the effect, effect end $_{\text {is }}$ the compliance level at which the maximum effect is reached, and $C$ is the current compliance level.

A detailed description of the management measures and the sublevels is given in the online data supplement (available at http://www.journalofdairyscience.org/ issues/contents?issue_key=S0022-0302(09)X0002-0).

\section{Costs of Management Measures}

For all management measures, costs were identified and calculated. All costs were calculated per year for a default Dutch dairy farm of 65 milking cows, with a milking parlor with 12 milking places. Costs were based on information from different suppliers. The expertise of the authors was used when no concrete information was available. The extra costs of milking clinical cases and subclinical cases last included labor time and the provision of a fence necessary to keep the cows separated. For using separate cloths for every cow, costs included extra labor and extra cloths, an increase over using one cloth for 6 cows. Cleaning a dirty udder with water and drying afterward included costs for labor, extra water use, and extra cloths for drying. For prestripping and cleaning the yards, only costs for labor were included. Wearing milkers' gloves only included costs for the gloves. Postmilking teat disinfection included costs for labor, teat dip, and the dip cup. The measures of manually rinsing the milking clusters after milking a 


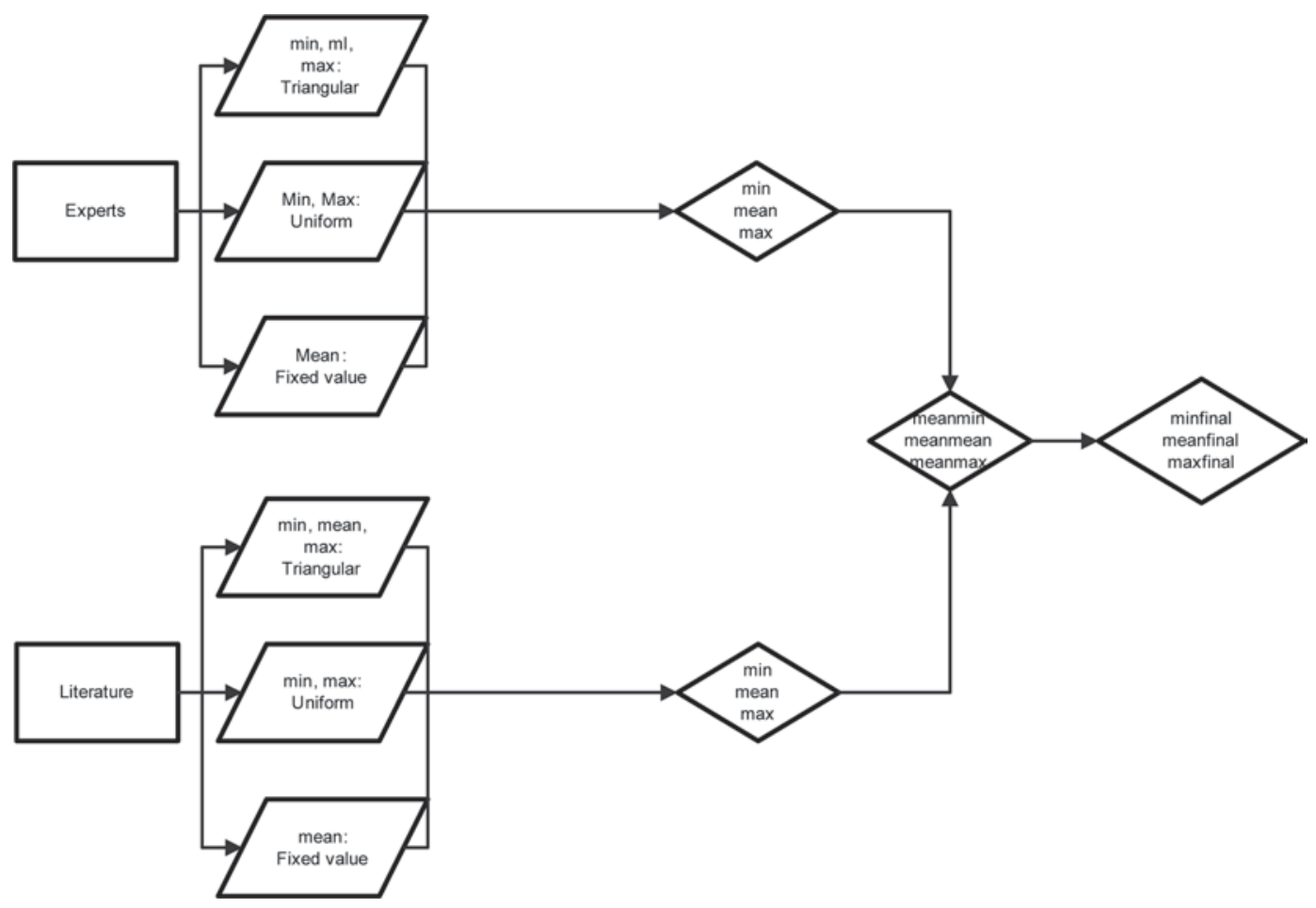

Figure 1. Schematic overview of Monte Carlo expert evaluation.

clinical case or after milking a subclinical case included costs for labor and water. Replacing teat cup liners as advised included costs for extra liners (compared with longer use) and labor. Costs of implementing a treatment protocol included costs for the veterinarian and labor of the farmer. For drying off with antibiotics, costs for the antibiotics and labor were included. To keep the cows standing after milking, extra costs for a more complex and expensive feed fence were included ( $30 \%$ of the costs). The costs for feeding dry cow minerals and optimizing the lactation feed consisted of extra feed and labor costs. Cleaning the stalls included costs for labor and for extra bedding material. The cost effects of decreasing overcrowding was calculated based on a lower milk production at the herd level, partly compensated by lower feeding costs, veterinarian costs, labor, and a compensation for not fulfilling the quota.

\section{Technical Efficiency of Management Measures: Data Envelopment Analysis}

Data envelopment analysis (DEA) is a widely used linear programming technique in operations research and economics for evaluating the technical and economic performance of producers. Producers are typically evaluated in terms of their ability to minimize the use of input need to produce a given quantity of output, or to maximize production of output from a given quantity of inputs. An important feature of the approach of DEA is that performance is judged in relative terms; that is, performance is measured relative to the best practice in a comparison group of producers. The method constructs a benchmark for each individual operation (in this case, a management measure) that is based on actual observed achievements in other operations (other management measures). This benchmark is called the best-practice frontier.

For this study, DEA was used to construct a measure of technical efficiency that allows for the comparison of mastitis control measures on the basis of their costs and efficacy. The input used in the DEA was the cost of the management measure per year. Two outputs were used: the percentage decrease in BTSCC and the percentage decrease in incidence of CM. These outputs were the result of the Monte Carlo expert evaluation analysis. As an illustration, Figure 2 presents 4 hypothetical management measures, each using 1 input (costs in $€$ / year) to produce 2 different outputs $\left(\mathrm{y}_{1}=\right.$ efficacy in percentage decrease in incidence of $\mathrm{CM}$, and $\mathrm{y}_{2}=$ efficacy on percentage decrease in BSTCC). Management measures $(\mathbf{m m})$ 1, 2, and 3 are benchmark measures: they are located on the best-practice frontier. Management measure 4 uses the same inputs as 1, 2, and 3 but produces less of both outputs; that is, this measure is in the interior of the output set, and is not as efficient as 1,2 , and 3 . The radial distance of $\mathrm{mm} 4$ from the best 


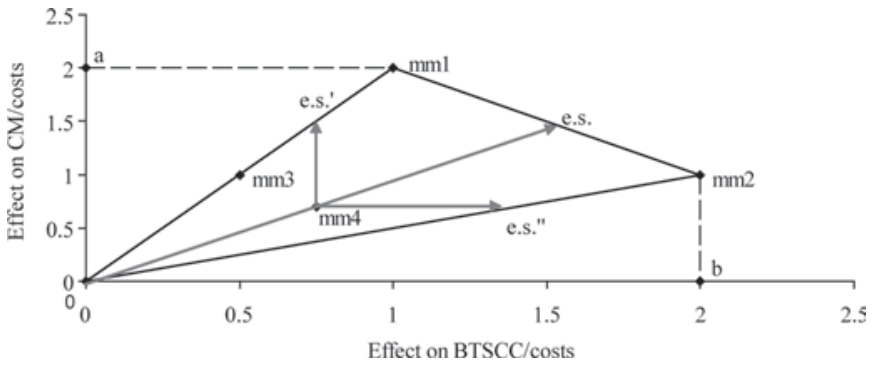

Figure 2. Graphical representation of the theoretical best-practice frontier; mm indicates different management measures with $\mathrm{mm} 1$, $\mathrm{mm} 2$, and $\mathrm{mm} 3$ being the benchmark measures, e.s. the overall efficiency score, e.s.' is the efficiency score for subvector $\mathrm{y}_{1}$, and e.s." is the efficiency score for subvector $\mathrm{y}_{2} . \mathrm{CM}=$ clinical mastitis; BTSCC $=$ bulk tank SCC

practice frontier, its technical efficiency, is given by 0e.s. $/ 0 \mathrm{~mm} 4$ (where e.s. is efficiency score), which can be thought of as the ratio of maximum potential output (at e.s.) to actual or observed output (at $\mathrm{mm} 4$ ). This measure is referred to as the Farrell output oriented measure of technical efficiency $\left[F_{0}(x, y)\right]$ :

$$
F_{0}(x, y \mid C, W)=\max \left\{\theta: \theta_{y} \in P(C, W)\right\},
$$

where $C$ refers to constant returns to scale (CRS), $W$ to weak disposability of output, and $\theta$ to a positive scalar reflecting the radial distance between the actual output and the output on the best-practice frontier.

Under CRS, proportional changes in inputs result in the same proportional changes in output. The assumption of CRS was made because sublevels of the management measures were included in the models to account for the variation. Weak disposability indicates that outputs cannot be disposed of without costs. The assumption of weak disposability was checked by assessing the extent to which the outputs are subject to congestion. This assessment revealed that the congestion efficiency was low, indicating that in some ranges of the production frontier, a reduction in the percentage of incidence of CM (percentage BTSCC) cannot be achieved without additional costs or without increasing the percentage BTSCC (percentage incidence of CM). The frontier under weak disposability is indicated as the triangle of black lines in Figure 2. The dashed line indicates the frontier under the assumption of strong disposability. In Figure 2, this would mean that mm3 would not be on the best-practice frontier under strong disposability, but is on the best-practice frontier under the assumption of weak disposability.

Under CRS and weak disposability of outputs, the output set for each management measure $(i)$ is described by:

$$
P\left(x_{i} \mid C, W\right)=\left\{y_{1 i}, y_{2 i}\right):
$$

$$
\begin{gathered}
\sum_{k=1}^{K} z_{k} y_{k m}=y_{i m}, m=1,2 \\
\sum_{k=1}^{K} z_{k} x_{k} \leq x_{i}, \\
\sum_{k=1}^{K} z_{k}=1 \\
z_{k} \geq 0, k=1, \ldots, K,
\end{gathered}
$$

where $K$ is the total number of management measures, $x$ is the input (costs), $m$ are the outputs (effect on decrease in incidence of $\mathrm{CM}$ and effect on decrease in BTSCC), and $z_{k}, k=1, \ldots, K$ are the intensity variables.

The above described output-based technical efficiency measure scaled each output with the same factor $\theta$. To calculate the efficiency of the management measures on the 2 individual outputs, subvector efficiency measures were introduced to generate technical efficiency measures for a subset of outputs rather than for the entire vector of outputs. Figure 2 presents the overall efficiency measure by line $\mathrm{mm} 4$ - e.s. When analyzing the subvector efficiency measure, this is split up in line $\mathrm{mm} 4$ - e.s." for subvector $\mathrm{y}_{2}$ and the line $\mathrm{mm} 4$ - e.s.' for subvector $\mathrm{y}_{1}$.

The analyses were carried out for 3 situations: 1) efficacies on BTSCC and incidence of CM for a default distribution of environmental and contagious pathogens, 2) efficacies on BTSCC and incidence of CM for a $100 \%$ environmental problem, and 3) efficacies on BTSCC and incidence of CM for a 100\% contagious problem.

\section{RESULTS}

A total of 436 papers were selected from the literature, of which 175 were unsuitable due to irrelevancy (e.g., because it was not original research or none of the selected management measures were included). In total, 218 papers were excluded because values could not be recalculated to a percentage decrease in incidence of $\mathrm{CM}$ or BTSCC. The recalculation could not be done because, for example, only relative risks or odd ratios were mentioned, without information about the number of animals or farms in the different groups. Therefore, it was not possible to recalculate this to a percentage decrease. In addition, some papers mentioned only an increase or decrease in incidence of CM or BTSCC without quantifying this effect. Therefore, 43 papers were used in this study and were included as inputs for the Monte Carlo expert evaluation analysis. During the 3 expert sessions, 15 experts were surveyed on the 
efficiencies. Table 2 presents the combined effects from the literature and experts for the different management measures. The effects of the management measures are given as a percentage decrease in incidence of $\mathrm{CM}$ and as a percentage decrease of BTSCC for a $100 \%$ environmental and a 100\% contagious situation. On average, postmilking teat disinfection had the largest effect in terms of a decrease in incidence of CM and BTSCC for both an environmental and a contagious problem. Wearing milkers' gloves had the smallest effect on CM for both an environmental and contagious problem. Using a separate cloth had the smallest effect on BTSCC with an environmental problem, and cleaning the yards twice a day had the smallest effect on BTSCC for a contagious problem. The ranking of the management measures varied between the different situations (milking subclinical cases last for an effect on BTSCC or for an effect on incidence of $\mathrm{CM}$ with an environmental problem). For all management measures in all situations, a large variance (min; max) was found, indicating the uncertainty and variation of the efficacies.

The effects of an imperfect compliance of the management measures are presented in Table 1. Imperfect compliance had a linear effect on most management measures, except for wearing milkers' gloves and for keeping cows standing, which had binary effects, and for postmilking teat disinfection, dry cow minerals, overcrowding, and optimizing feed, which had S-curve effects. Costs of the management measure are presented in Table 3 as labor costs, expenditures, and total costs. Total costs varied between $€ 34$ (rinse clusters CM) and $€ 7,994$ (rinse clusters subclinical). Some management measures (prestripping and cleaning yards) consisted only of labor costs and therefore the expenditures were set to $€ 0$. For other management measures, expenditures varied between $€ 10$ (rinse clusters $\mathrm{CM}$ ) and $€$ 2,300 (rinse clusters subclinical).

Results of the DEA analyses are graphically depicted in Figure 3. This figure shows the most cost-efficient management measures (rinse clusters clinical, separate cloth, keep cows standing, and wearing milkers' gloves) in a default situation as the best-practice frontier. The other management measures are also presented. The greater the distance to the best-practice frontier, the less cost-efficient the management measure is.

Results of the DEA analysis, assuming 100\% compliance of the management measures, are presented in Table 4. According to these results, 4 management measures had an efficiency score of 1 in the default situation, which means they had the highest overall efficacy relative to their costs and describe the best-practice frontier. Management measures with an efficiency score of 1 are optimal. A management measure with a score of 0.34 (wash dirty udder) loses $66 \%$ of cost-efficiency

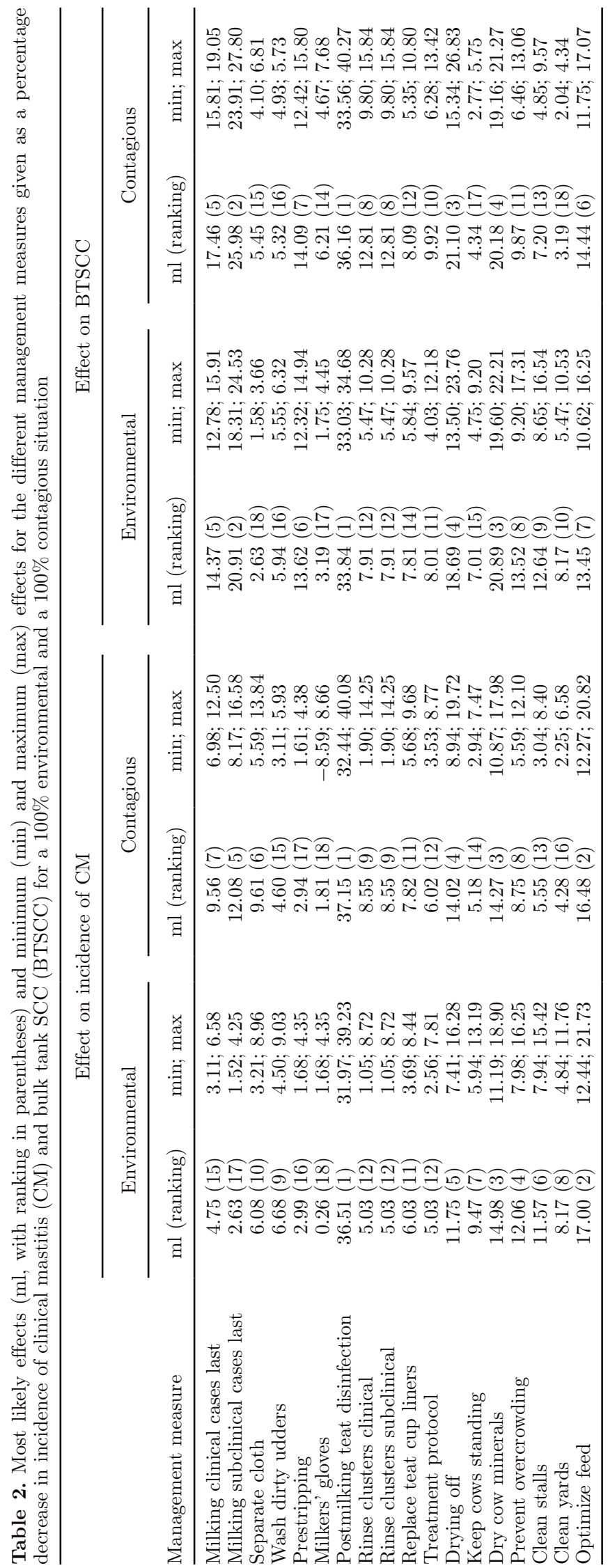


Table 3. Costs for implementing the management measures, given as labor costs ( $€ /$ year), expenditure $(€ /$ year $)$, and total costs $(€ /$ year $)$ for a dairy farm of 65 milking cows with a 12-place milking parlor under Dutch conditions

\begin{tabular}{|c|c|c|c|}
\hline \multirow[b]{2}{*}{ Management measure } & \multicolumn{3}{|c|}{ Costs $(€ /$ year $)$} \\
\hline & Labor & Expenditures & Total \\
\hline Milking clinical cases last & 2,190 & 200 & 2,390 \\
\hline Milking subclinical cases last & 6,570 & 200 & 6,770 \\
\hline Separate cloth & 237 & 1,424 & 1,661 \\
\hline Wash dirty udders & 142 & 58 & 200 \\
\hline Prestripping & 2,190 & 0 & 2,190 \\
\hline Milkers' gloves & 0 & 73 & 73 \\
\hline Postmilking teat disinfection & 949 & 1,095 & 2,044 \\
\hline Rinse clusters clinical & 24 & 10 & 34 \\
\hline Rinse clusters subclinical & 5,695 & 2,300 & 7,994 \\
\hline Replace teat cup liners & 108 & 720 & 828 \\
\hline Treatment protocol & 144 & 360 & 464 \\
\hline Drying off & 36 & 560 & 596 \\
\hline Keep cows standing & 0 & 109 & 109 \\
\hline Dry cow minerals & 108 & 750 & 858 \\
\hline Prevent overcrowding & 250 & 1,250 & 1,500 \\
\hline Clean stalls & 3,285 & 200 & 3,485 \\
\hline Clean yards & 3,285 & 0 & 3,285 \\
\hline Optimize feed & 108 & 1,473 & 1,581 \\
\hline
\end{tabular}

compared with the most efficient management measures. Lower costs of labor (set to €5 instead of €18) did not influence the management measures describing the best-practice frontier, but had some effect on the efficiency scores of the other management measures (e.g., prestripping).
Table 5 presents the DEA results for the top 25 management measures (regarding efficiency scores) including imperfect levels of compliance. Of the 25 management measures, 8 were $100 \%$ compliance measures. The other management measures were sublevels of these 8 . The 10 highest ranked management measures consisted

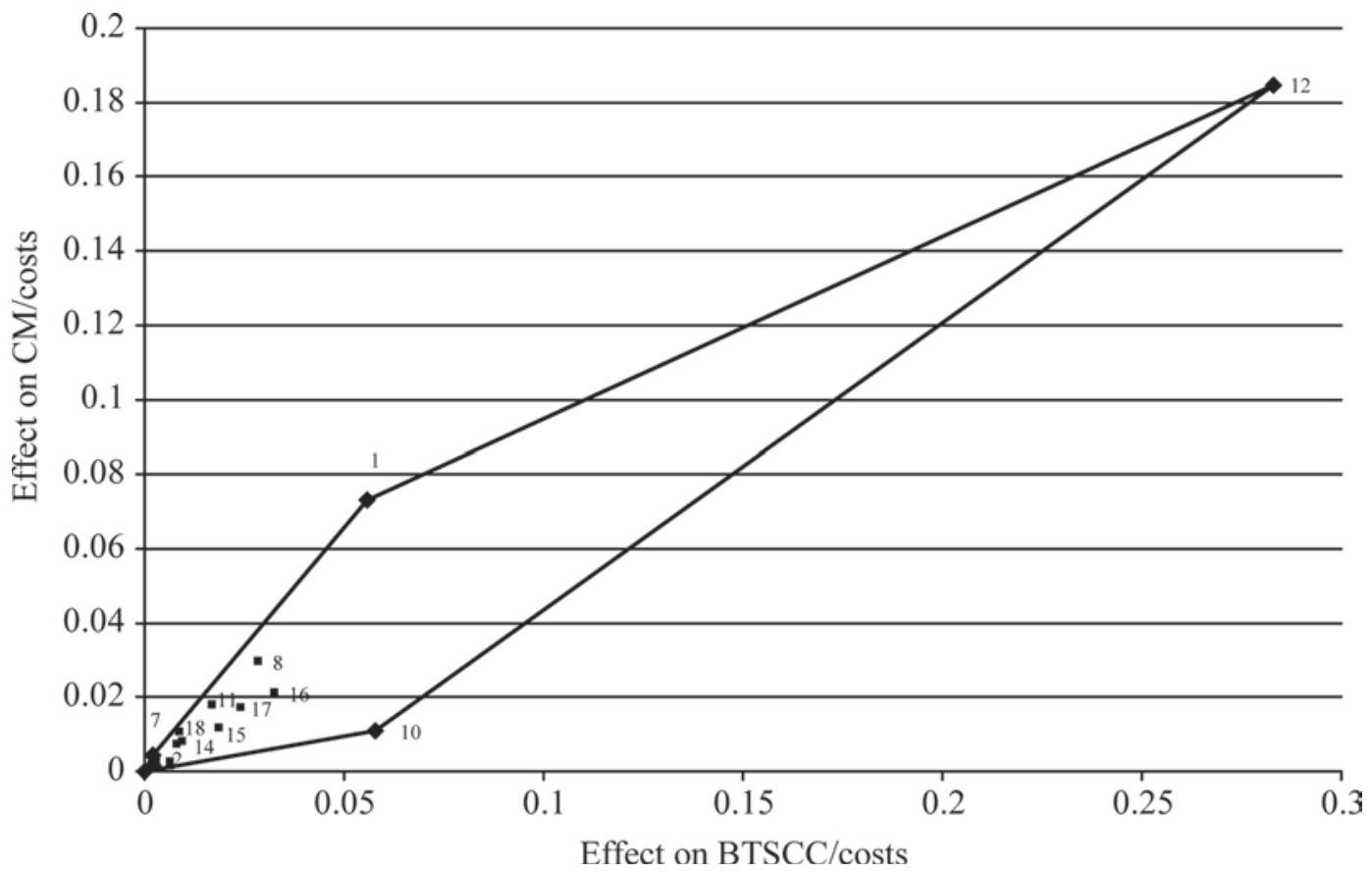

Figure 3. Best-practice frontier of the management measures assuming $100 \%$ compliance, where $\mathrm{y}_{1}=$ percentage decrease in incidence in clinical mastitis $(\mathrm{CM}), \mathrm{y}_{2}=$ percentage decrease in bulk tank SCC (BTSCC); $1=$ keep cows standing, $2=$ prevent overcrowding, $3=$ clean stalls, $4=$ clean yards, $5=$ milking clinical cases last, $6=$ milking subclinical cases last, $7=$ separate cloth, $8=$ wash dirty udder, $9=$ prestripping, $10=$ milkers' gloves, $11=$ postmilking teat disinfection, $12=$ rinse clusters clinical, $13=$ rinse clusters subclinical, $14=$ replace teat cup liners, $15=$ treatment protocol, $16=$ drying off, $17=$ dry cow minerals, and $18=$ optimize feed. 
Table 4. Efficiency scores resulting from the data envelopment analysis under constant returns to scale and weak disposability of management measures assuming $100 \%$ compliance for a default situation, a $100 \%$ environmental problem, and a $100 \%$ contagious problem, and with assumed lower costs of labor (€5; Default_ lowlab)

\begin{tabular}{lcccc}
\hline Management measure & Default & Environmental & Contagious & Default_lowlab \\
\hline Rinse clusters clinical & 1.00 & 1.00 & 1.00 & 1.00 \\
Separate cloth & 1.00 & 1.00 & 1.00 & 1.00 \\
Keep cows standing & 1.00 & 1.00 & 1.00 & 1.00 \\
Milkers' gloves & 1.00 & 1.00 & 1.00 & 1.00 \\
Wash dirty udder & 0.34 & 0.68 & 0.54 & 0.66 \\
Postmilking teat disinfection & 0.21 & 0.26 & 0.46 & 0.30 \\
Optimize feed & 0.14 & 0.12 & 0.22 & 0.14 \\
Drying off & 0.13 & 0.08 & 0.05 & 0.07 \\
Dry cow minerals & 0.12 & 0.10 & 0.08 & 0.09 \\
Prestripping & 0.10 & 0.40 & 1.00 & 0.37 \\
Treatment protocol & 0.08 & 0.05 & 0.09 & 0.07 \\
Replace teat cup liners & 0.07 & 0.05 & 0.16 & 0.07 \\
Milking clinical cases last & 0.07 & 0.24 & 0.10 & 0.18 \\
Prevent overcrowding & 0.07 & 0.06 & 0.07 & 0.06 \\
Milking subclinical cases last & 0.05 & 0.22 & 0.09 & 0.17 \\
Clean stalls & 0.03 & 0.08 & 0.04 & 0.07 \\
Clean yards & 0.02 & 0.08 & 0.29 & 0.08 \\
Rinse clusters subclinical & 0.00 & 0.00 & 0.00 & 0.00 \\
\hline
\end{tabular}

of using separate cloths and rinse clusters clinical at all sublevels of compliance, as well as wearing milkers' gloves and keeping cows standing both at $100 \%$ compliance. The other management measures consisted of all sublevels of wash dirty udders and prestripping, the upper 3 sublevels of postmilking teat disinfection, the upper 2 sublevels of optimizing feed, replacing teat cup liners $(25 \%)$, and dry cow minerals $(75 \%)$.

Results of the subvector analysis are presented in Table 6 and show that of the 4 management measures with an efficiency score of 1 in the default situation, only rinse cluster clinical had an efficiency score of 1 for both subvectors. The other management measures were shown to be more important to 1 of the 2 subvectors.

\section{DISCUSSION}

This study gives a comprehensive overview of the efficacies of 18 management measures on BTSCC and the incidence of CM. It would not be realistic to try to describe all possible management measures to decrease mastitis incidence, nor would it add value. The 18 most important management measures were selected using the National Mastitis Council 10-point plan and the management measures advised by the Dutch Udder Health Center. Other farm characteristics not included in the present study can influence the efficiency scores of the management measures. One of those characteristics is the current udder health situation. Management measures will have more effect on farms with a bad udder health situation (high BTSCC, high incidence of CM, or both) than on farms that already have a good udder health situation. The efficacies included in our study were based on the situations in an average herd, and the uncertainty of these efficacies was taken into account. The best method to quantify the effect of management measures from literature is to perform a meta-analysis, for which data from at least 5 papers are needed. For most of the management measures, insufficient literature data are available to perform a meta-analysis. Thus, the efficacies were based on a combination of literature and expertise. Although for some management measures (e.g., treatment protocol), no literature data were available, for other measures (e.g., postmilking teat disinfection), many papers with data have been published. This difference can result in bias in the papers included in the study, as the included papers are not representative of the entire realm of mastitis research. This problem is dealt with by combining the data from literature with expertise. It was not possible to include more papers because of 2 important reasons. The first reason was irrelevancy of the paper for the aim of our study. This does have a positive effect that only more relevant and more representative papers were included. The second reason to exclude papers was that the percentage decrease in incidence of $\mathrm{CM}$ or BTSCC could not be subscribed to one of the included management measures. By presenting the minimum and maximum effects of the management measures in different farm situations, insight into the uncertainty of the described effects of management measures was given. Additionally, when using data from literature, it has to be realized that publication bias might exist (Halasa et al., 2009b). Thus, a combination of data from literature combined with expert opinions is both inevitable and desirable.

On average, postmilking teat disinfection had the largest effect on a decrease in incidence of $\mathrm{CM}$ and 
Table 5. Efficiency scores resulting from the data envelopment analysis for the top 25 management measures (compliance level indicated in parentheses)

\begin{tabular}{lccc}
\hline Management measure & Default & Environmental & Contagious \\
\hline Separate cloth (50\%) & 1.00 & 0.99 & 0.37 \\
Milkers' gloves (100\%) & 1.00 & 1.00 & 1.00 \\
Rinse clusters clinical (50\%) & 1.00 & 1.00 & 1.00 \\
Rinse clusters clinical (25\%) & 1.00 & 1.00 & 1.00 \\
Keep cows standing (100\%) & 1.00 & 1.00 & 1.00 \\
Separate cloth (75\%) & 0.99 & 1.00 & 0.37 \\
Rinse clusters clinical (75\%) & 0.75 & 0.75 & 0.76 \\
Separate cloth (100\%) & 0.71 & 0.71 & 0.27 \\
Separate cloth (25\%) & 0.71 & 0.71 & 0.27 \\
Rinse clusters clinical (100\%) & 0.50 & 0.50 & 0.51 \\
Wash dirty udder (75\%) & 0.39 & 0.40 & 0.32 \\
Wash dirty udder (50\%) & 0.34 & 0.36 & 0.28 \\
Wash dirty udder (100\%) & 0.32 & 0.33 & 0.26 \\
Wash dirty udder (25\%) & 0.28 & 0.29 & 0.23 \\
Postmilking teat disinfection (75\%) & 0.22 & 0.19 & 0.34 \\
Postmilking teat disinfection (50\%) & 0.20 & 0.17 & 0.31 \\
Postmilking teat disinfection (100\%) & 0.20 & 0.17 & 0.31 \\
Optimize feed (75\%) & 0.15 & 0.13 & 0.22 \\
Optimize feed (100\%) & 0.14 & 0.12 & 0.20 \\
Prestripping (25\%) & 0.10 & 0.11 & 0.99 \\
Prestripping (100\%) & 0.10 & 0.11 & 1.00 \\
Prestripping (75\%) & 0.10 & 0.11 & 1.00 \\
Prestripping (50\%) & 0.10 & 0.11 & 0.99 \\
Replace teat cup liners (25\%) & 0.10 & 0.07 & 1.00 \\
Dry cow minerals (75\%) & 0.10 & 0.11 & 0.09 \\
\hline
\end{tabular}

BTSCC for both an environmental and a contagious problem. Postmilking teat disinfection was also the management measure for which the most references (13) were available. Also for drying off, relatively more data were available from the literature (10 papers), but the effects found for drying off were lower (ranking between 3 and 5 depending on the situation). Wearing milkers' gloves had the smallest effect on CM, for both an environmental and a contagious problem. Only a few papers (3) were available for our study that described the effects of wearing milkers' gloves. The variation in these effects was large and some effects found were even negative (Peeler et al., 2000; O'Reilly et al., 2006). Because these negative effects were also included in the analysis, this caused the low ranking based on the calculated most likely values.

Using a separate cloth had the smallest effect on a BTSCC problem with an environmental background, and cleaning the yards twice a day had the smallest effect on BTSCC due to a contagious problem. The ranking of the management measures varied between the different situations (milking subclinical cases last for an effect on BTSCC or for an effect on incidence of CM caused by an environmental problem). This indicates that it is important to take into account farmspecific characteristics. For all management measures in all situations, large variance was found, indicating the uncertainty of the efficacies. This indicates the variation that occurred when papers were included that found different effects (e.g., postmilking teat disinfec- tion and drying off). It also indicates uncertainty when only (or mostly) expertise was used to determine the effects. This was the case, for example, for prevention of overcrowding and optimization of feed for which no references from the literature could be used. Both of these measures were ranked highly. It would be useful to gather more concrete information in the field about the effects of these measures. Then it would be possible

Table 6. Efficiency scores resulting from the data envelopment analysis of the default situation, with only management measures with $100 \%$ compliance included, including both outputs and efficiency scores for the 2 subvectors [bulk tank somatic cell count (BTSCC) and incidence of clinical mastitis $(\mathrm{CM})]$

\begin{tabular}{lccc}
\hline Management measure & Default & CM & BTSCC \\
\hline Separate cloth & 1.00 & 1.00 & 0.09 \\
Milkers' gloves & 1.00 & 0.15 & 1.00 \\
Rinse clusters clinical & 1.00 & 1.00 & 1.00 \\
Keep cows standing & 1.00 & 1.00 & 0.40 \\
Wash dirty udder & 0.34 & 0.78 & 0.35 \\
Postmilking teat disinfection & 0.21 & 0.77 & 0.25 \\
Optimize feed & 0.14 & 0.83 & 0.16 \\
Drying off & 0.13 & 0.48 & 0.46 \\
Dry cow mineral & 0.12 & 0.53 & 0.36 \\
Prestripping & 0.10 & 0.14 & 0.88 \\
Treatment protocol & 0.08 & 0.45 & 0.32 \\
Replace teat cup liners & 0.07 & 0.58 & 0.23 \\
Prevent overcrowding & 0.07 & 0.61 & 0.21 \\
Milking clinical cases last & 0.07 & 0.27 & 0.45 \\
Milking subclinical cases last & 0.05 & 0.15 & 0.72 \\
Clean stalls & 0.03 & 0.49 & 0.22 \\
Clean yards & 0.02 & 0.53 & 0.18 \\
Rinse clusters subclinical & 0.00 & 0.32 & 0.29 \\
\hline
\end{tabular}


to improve the accuracy of the models and thus the accuracy of the resulting advice.

On average, the efficacies that came from experts were lower than the values from the available literature. This was not a significant difference but could indicate a lack of confidence in the management measures by the experts. Only for separate cloth, milkers' gloves, and rinse clusters (clinical and subclinical) were the values derived from the experts slightly higher than the values found in the literature.

Data envelopment analysis is commonly used in applied (agricultural) economics but is a new method in the field of dairy science. The method can be used to analyze efficient dairy producers as was done by Stokes et al. (2007), but it is also very useful to analyze the costefficiency of management measures at the farm level, as is done in this study. One of the characteristics of DEA is that the efficiencies are evaluated relative to the performance of other management measures. Thus, when new management measures are included in the analysis, the efficiency scores for all management measures may change. The method constructs a best-practice frontier for each individual management measure that is based on actual observed effects within a group of similar management measures. An output-oriented measure of efficiency was used, meaning that for a given level of resources used, the best-practice frontier management measures are those that have the highest efficacies. The output-oriented approach was used because this approach best reflects reality. Farmers want to have the greatest effect from the budget they have available. In standard advice, however, costs of management measures in relation to their effect are rarely taken into account. Measures are often proposed based on their assumed effect or are discouraged because of high costs, when cost-efficiency is often not taken into account. Results show that management measures with the largest effect are not necessarily the ones with best efficacy in relation to the costs. The clearest example in this study is postmilking teat disinfection. Although it shows, by far, the highest efficacy in all situations, it is not a measure forming the best-practice frontier and thus is not a costefficient measure. However, wearing milkers' gloves has a much lower effect but this measure is very cost-efficient because the associated costs are low.

When calculating costs of management measures, labor is a difficult factor to take into account, mainly because it is difficult to determine an hourly rate. In agriculture, opportunity costs are rather small and often set to zero. The sensitivity of the results for the assumed costs of labor was verified by setting it at a low value $(€ 5)$. The results indicated that the same management measures formed the best-practice frontier. In our study, only efficacies and costs were included; benefits derived from a decrease in incidence of $\mathrm{CM}$ or BTSCC were not included.

\section{CONCLUSIONS}

Management measures with the highest efficacy are not necessarily the ones with highest cost-efficiency. Results show that some management measures with a high efficacy (e.g., postmilking teat disinfection) are not necessarily cost-efficient because of their high associated costs, whereas measures with lower efficacy (e.g., milkers' gloves) and lower associated costs are cost-efficient. When management measures are advised without taking into account their associated costs, the ranking of management measures will differ from the ranking when costs are taken into account. In a herd with an average udder health situation, the most costefficient measures are rinse clusters CM, use separate cloth, keep cows standing, and wearing milkers' gloves.

\section{ACKNOWLEDGMENTS}

This study is part of the five-year mastitis program of the Dutch Udder Health Centre and was financially supported by the Dutch Dairy Board. The authors thank the experts who participated in the different expert sessions and Ingrid van Dixhoorn, Rudi de Mol, Wijbrand Ouweltjes, Judith Poelarends, and Betsie Slaghuis from the Animal Sciences Group (Lelystad, the Netherlands) for their work on the literature review. Finally, we thank Eimear Murphy for her English language check.

\section{REFERENCES}

Barkema, H. W., Y. H. Schukken, T. J. G. M. Lam, M. L. Beiboer, G. Benedictus, and A. Brand. 1999. Management practices associated with the incidence rate of clinical mastitis. J. Dairy Sci. 82:16431654 .

Barnouin, J., S. Bord, S. Bazin, and H. Chassagne. 2005. Dairy management practices associated with incidence rate of clinical mastitis in low somatic cell count herds in France. J. Dairy Sci. 88:3700-3709.

Halasa, T., K. Huijps, O. Østerås, and H. Hogeveen. 2007. Economic effects of bovine mastitis and mastitis management: A review. Vet. Q. 29:18-31.

Halasa, T., O. Østerås, H. Hogeveen, T. van Werven, and M. Nielen. 2009b. Meta-analysis of dry cow management for dairy cattle. Part 1. Protection against new intramammary infections. J. Dairy Sci. 92:3134-3149.

O'Reilly, K. M., M. J. Green, E. J. Peeler, J. L. Fitzpatrick, and L. E. Green. 2006. Investigation of risk factors for clinical mastitis in British dairy herds with bulk milk somatic cell counts less than 150,000 cells/ml. Vet. Rec. 158:649-653.

Peeler, E. J., M. J. Green, J. L. Fitzpatrick, K. L. Morgan, and L. E. Green. 2000. Risk factors associated with clinical mastitis in low somatic cell count British dairy herds. J. Dairy Sci. 83:2464-2472.

Seabrook, M. F. 1984. The psychological interaction between the stockman and his animals and its influence on performance of pigs and dairy cows. Vet. Rec. 155:84-87.

Stokes, J. R., P. R. Tozer, and J. Hyde. 2007. Identifying efficient dairy producers using data envelopment analysis. J. Dairy Sci. 90:2555-2562. 